\title{
A Simulation System of Surface Texture on Face Milling Yimin $\mathrm{Ma}^{1, \mathrm{a}}$ \\ ${ }^{1}$ Engineering University of Armed Police Force, Xian 710086, China \\ ama_yimin@126.com
}

Keywords: surface milling tools; simulation system; surface texture

\begin{abstract}
Based on the surface milling tools, this paper establishes the corresponding mathematical model, constructs milling simulation algorithm, and further discusses the influence of the feed and interval feed. Through the thorough and deep analysis, the novel milling surface simulation system is finally developed, which is meaningful to forecast the roughness and improve the surface quality.
\end{abstract}

\section{Introduction}

Evaluation of the workpiece surface roughness is one of the most important indicators of the quality of machined surface, and it depends on the geometry of the microscopic morphology of the surface to be machined parts [1]. Generally, the workpiece is completed by experimental measurements, which is meaningful to improve surface quality. Milling machining is one of the most commonly used processing methods. The range of milling process is relatively wide and high processing efficient. A variety of complex contoured surface can be selected, but due to the use of multi-tooth milling cutter, which depends on the geometry of the machined surface morphology used in tool geometry and the choice of cutting the amount [2]. The current milling geometry surface topography simulation focuses on ball milling conditions [3, 4]. However, there are few the researches of face milling cutter surface geometric morphology simulation. Therefore, this paper provide reliable reference of predicting and improving the machined surface morphology based on the face milling which is the most basic type.

\section{Simulation modeling}

When parsing the machined surface morphology, the blade represented by curve. The track of cutting edge is a space complex surface formed in the movement track scanning at one point along the curve of the blade curve trajectory. In the simulation process, the three-dimensional mesh is generated on the surface, comparing the relative position of sweeping curved space and space squares, then removed the point at the top of surface, checkbox point beneath the surface is formed the surface morphology [5].

\section{A. blade modeling based on coordinate system}

\section{(1) mathematical expression of face milling blade}

Figure 1 is indexable face milling cutter, figure 2 is three different shapes of blades -square, circle, equilateral triangle. According to different blade shape, mathematical models were established. Figure 3, $\mathrm{O}_{\mathrm{T}}-\mathrm{UVW}$ is the tool coordinate system, $\mathrm{O}_{\mathrm{W}}-\mathrm{XYZ}$ is coordinate system of workpiece.

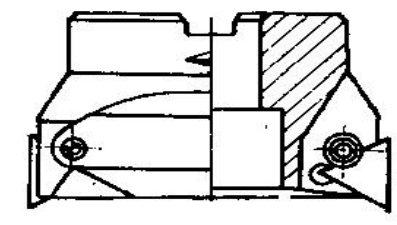

Fig. 1 Face Milling Tool 


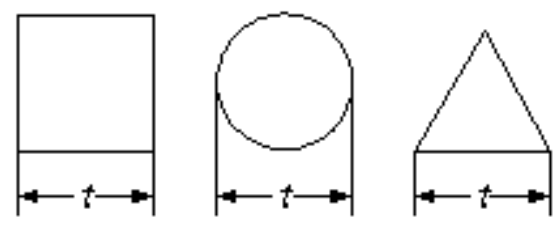

Fig. 2 Shape of Tools

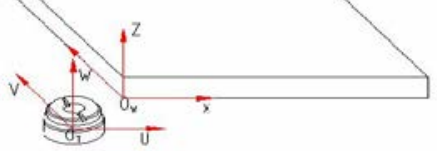

Fig. 3 Coordinate System

For a triangle or square blade, under the tool coordinate system, any point of the blade coordinates is:

$$
\begin{aligned}
& \left\{\begin{array}{l}
\mathrm{w}=\mathrm{u} * \tan \mathrm{Kr}+\mathrm{D} / 2 \\
\mathrm{v}=0
\end{array}\right. \\
& \left\{\begin{array}{l}
\mathrm{w}=\mathrm{u} * \tan (\mathrm{Kr}+\theta)+\mathrm{D} / 2 \\
\mathrm{v}=0
\end{array}\right.
\end{aligned}
$$

For a circular blade:

$$
\left\{\begin{array}{l}
u=R \cos \alpha \\
v=0 \\
w=R \sin \alpha+R
\end{array}\right.
$$

Where, $\mathrm{Kr}$ is the front rake angle of the tool, $\mathrm{D}$ is the cutter radius, $R$ is the circular blade edge length, $\alpha$ is position angle, for triangular and square blade, outer edge is represented by formula (1), inner edge is represented by formula (2), $\theta$ is angle of the inner edge and the outer edge.

(2) General expression under the blade of the tool coordinate system

In order to facilitate the simulation, we grant the initial phase angle is zero. Therefore, at any time $t$, the $i$ feeds, phase angle for the $j$ blade:

$$
\varphi_{i, j}=\omega t+2 \pi(\mathrm{j}-1) / \mathrm{f}_{z}+\Psi_{i, j}
$$

Where, $\omega$ is angular velocity of the tool, $f_{z}$ is the number of teeth of the tool, $\Psi_{i, j}$ is the phase angle when first feed, in order to facilitate the simulation, and generally $\Psi_{i, j}=0$.

Therefore, in the tool coordinate system, at each edge of the coordinate value of any point $P$ (U, $\mathrm{V}, \mathrm{W})$ as follows:

$$
\left[\begin{array}{c}
U \\
V \\
W
\end{array}\right]=\left[\begin{array}{ccc}
\cos \varphi_{i, j} & -\sin \varphi_{i, j} & 0 \\
\sin \varphi_{i, j} & \cos \varphi_{i, j} & 0 \\
0 & 0 & 1
\end{array}\right]\left[\begin{array}{c}
u \\
v \\
w
\end{array}\right]
$$

\section{B. modeling tool sharpening shaped workpiece coordinate system}

Cutting tool if you only feed the same direction, it is called a single direction feed; if the feed in opposite directions, called to feed. The tool along the Y-axis positive direction feed called positive feed, negative direction called negative feed.

For one-way feed: 


$$
\left\{\begin{aligned}
x_{\text {OT }}= & x_{o}+(i-1) f_{p}+L x / 2 \\
y_{O T}= & y_{0}+ \\
& \quad f[t-(i-1)(\Delta t+L y / f)]-D / 2 \\
z_{O T}= & z_{0}
\end{aligned}\right.
$$

For two-way feed:

$$
\left\{\begin{aligned}
x_{o T}= & x_{o}+(i-1) f_{p}+L x / 2 \\
y_{o T}= & y_{0}+\left\{\left[1+(-1)^{i}\right] L y / 2+\right. \\
& \left.(-1)^{i+1} f[t-(i-1)(\Delta t+L y / f)]\right\}-D / 2 \\
z_{o T}= & z_{0}
\end{aligned}\right.
$$

Wherein $L y$ is a width of the workpiece, $\Delta t$ is the intervals of feed, $f$ is the spindle feed rate, $i$ is the number of feed, $\left(x_{0}, y_{0}, z_{0}\right)$ is the center coordinate values of the tool when feed for the first time, simulation when taking $x_{0}=L_{x} / 2, y_{0}=-\mathrm{D} / 2, z_{0}=0, i=1$.

For all cases mentioned above, the blade at any point $\mathrm{P}$ in the workpiece coordinate system can be used the following formula:

$$
\mathbf{H}=\left[\begin{array}{c}
X \\
Y \\
Z
\end{array}\right]=\left[\begin{array}{c}
U \\
V \\
W
\end{array}\right]+\left[\begin{array}{c}
x_{O T} \\
y_{O T} \\
Z_{O T}
\end{array}\right]
$$

Wherein, $[\mathrm{U}, \mathrm{V}, \mathrm{W}],\left[x_{0 T}, y_{0 T}, \mathrm{Z}_{0 T}\right]$ are regarded by (5)-(7).

\section{Simulation Algorithm}

Compared the $\mathrm{z}$ value of the tool trajectory and corresponding value in the matrix $\mathbf{H}$, the smaller element in the matrix $\mathbf{H}$ is saved, the last value in the matrix $\mathbf{H}$ is the height of the surface of the corresponding point of the residual, and then use straight lines connecting these points together to form a surface topography.

Representing the shape of the machined surface of residual matrix $\mathbf{H}$ of the height, Ra, roughness of the workpiece surface, represented by difference between the maximum and minimum .Therefore, according to the previous simulation algorithm can further predict the workpiece surface roughness, which is significative of the actual production and processing.

\section{Simulation results}

From the above simulation results, when the same cutting conditions, the same geometric conditions (the blade edge radius of the triangular blade and square is equal to the circular blade length), the roughness of the triangle is maximum, square followed, circular shaped is minimum. The quality of milling surface increases with the number of blades is getting better. In the same cutting conditions, feed rate, the greater roughness.

Table 1 Simulation Condition

\begin{tabular}{ccccccccc}
\hline $\begin{array}{c}\text { Figure } \\
\text { No. }\end{array}$ & $\begin{array}{c}\text { Spindle } \\
\text { Speed } \\
(\mathrm{r} / \mathrm{min})\end{array}$ & $\begin{array}{c}\text { Feed Rate } \\
(\mathrm{mm} / \mathrm{min})\end{array}$ & $\begin{array}{c}\text { Diameter } \\
\text { Cutter } \\
(\mathrm{mm})\end{array}$ & $\begin{array}{c}\text { Blade } \\
\text { Side } \\
(\mathrm{mm})\end{array}$ & $\begin{array}{c}\text { Tool } \\
\text { Flutes } \\
(\text { piece })\end{array}$ & $\begin{array}{c}\text { Amount } \\
\text { of Cut } \\
(\mathrm{mm})\end{array}$ & $\begin{array}{c}\text { Blade } \\
\text { Shape }\end{array}$ & $\begin{array}{c}\text { Roughness } \\
\text { Ra( } \mu \mathrm{m})\end{array}$ \\
\hline Fig. 4 & 500 & 500 & 80 & 12 & 3 & 3 & Triangle & 624.3 \\
Fig. 5 & 500 & 500 & 80 & 12 & 4 & 3 & Triangle & 312.5 \\
Fig. 6 & 500 & 500 & 80 & 12 & 3 & 3 & Square & 368.9 \\
Fig. 7 & 500 & 500 & 80 & 12 & 3 & 3 & Round & 11.8 \\
\hline
\end{tabular}




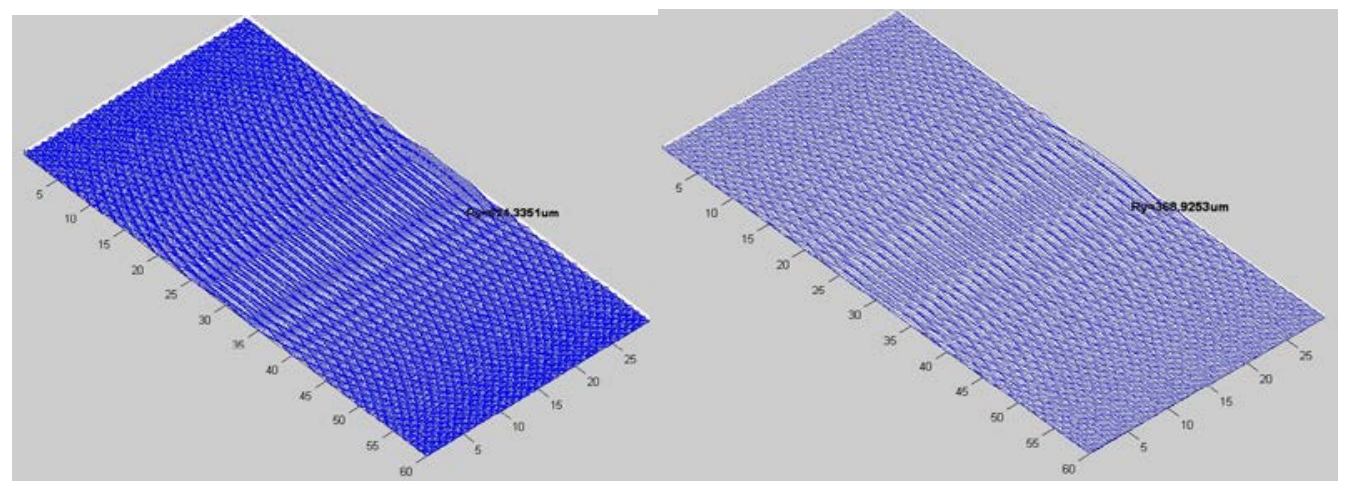

Fig. 4 Surface Texture

Fig. 5 Surface Texture

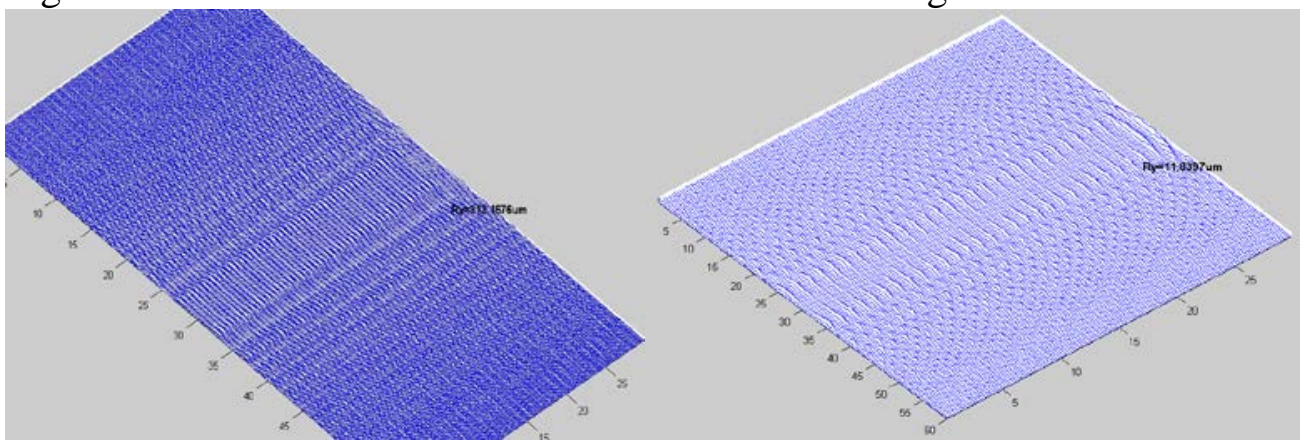

Fig. 6 Surface Texture

Fig. 7 Surface Texture

\section{Summary}

In this paper, a mathematical model of milling process and corresponding simulation algorithms has been established and the simulation system of face milling toolpaths have also been developed. By the above work, the shape and roughness of the machined surface residual can be easily measured. Moreover, the degree of roughness can be predicted more conveniently. Throgugh the test, it is sure that the system has the fast operation, intuitive graphical display and so on.

The milling the surface topography simulation system in this paper can predict surface quality, which has major significance optimizing the cutting parameters. This method is versatile and can be extended to other processing methods, especially to the control of the quality of the machined surface in precision machining.

\section{References}

[1] Meifa H, Xiong C, Huifen L, et al. Comparative analysis of evaluation method for surface topography[J]. Mechenical Design, 2012,29(5): 6-10.

[2] Houwei Z, Song Z, Gaoqi W, et al. Effect of machining inclination angle of ball-nose end mill on surface topography[J]. Computer Integrated Manufacturing, 2013,19(10): 2438-2444.

[3] Dong G. Toporaphy Simulation and Parameters optimization for Fly-cutting[D]. GuagnZhou: Guangdong University of Technology, 2014.

[4] Vopát T, J P, V i. Influence of form Factor of the Cutting Edge on Tool Life during Finishing Milling[J]. Procedia Engineering, 2015,100: 868-876.

[5] Junyun C, Qingliang Z. Investigation of Surface Roughness in Single Point Diamond Turning[J]. Journal of Beijing University of Technology, 2012,28(7): 1013-1019. 